\title{
Conclusion: Comparing Household Energy Use Across Europe-Uncovering Opportunities for Sustainable Transformation
}

\author{
Patrick Naef, Marlyne Sabakian \\ and Gary Goggins
}

\begin{abstract}
This chapter considers the similarities and differences between ten European countries in relation to meso-level considerations when it comes to household energy usage. We uncover the governing frameworks and policies related to energy usage, then examine socio-demographic characteristics including housing tenure and location. Next, we consider
\end{abstract}

P. Naef $(\bowtie) \cdot$ M. Sahakian

University of Geneva, Institute of Sociological Research,

Geneva, Switzerland

e-mail: patrick.naef@unige.ch

M. Sahakian

e-mail: Marlyne.Sahakian@unige.ch

G. Goggins

School of Geography and Archaeology and Ryan Institute,

National University of Ireland Galway, Galway, Ireland

e-mail: gary.goggins@nuigalway.ie

(C) The Author(s) 2019

F. Fahy et al. (eds.), Energy Demand Challenges in Europe, https://doi.org/10.1007/978-3-030-20339-9_13 
the energy mix and material arrangements, such as building stocks, before turning to climatic considerations and the cost of energy. The conclusion highlights the importance of embedding energy usage in socio-material systems, tackling questions related to collective conventions, for example, as well as notions of sufficiency. While the policy and technological dimensions of energy distribution are easier to account for in country reviews, the collective conventions that hold together everyday practices that use energy services would merit further study.

Keywords Socio-material systems - Governing frameworks • Sustainable energy $\cdot$ Sufficiency $\cdot$ Europe

\section{INTRODUCTION}

Households across Europe are key actors in energy transitions towards reduced and improved energy usage, either through the introduction of more efficient technologies in the home, or through more transformative forms of change such as engagement in cooperative renewable energy production. This edited collection presents a series of case studies, which allow for a 'zooming in' around ten, country-specific framings on how energy transitions are being addressed. In this chapter, we 'zoom out' and consider similarities and differences between countries in relation to meso-level considerations. First, we focus on the governing frameworks and policies related to energy usage, then we examine socio-demographic characteristics including housing tenure and location. Next, we consider the energy mix and material arrangements, such as building stocks, before turning to climatic considerations and the cost of energy. The conclusion presents a summary discussion around how these different elements of practices inter-relate, while also noting the lack of comparable data on collective conventions across the countries-an important but often neglected dimension of household energy usage.

\section{Governing Frameworks and Policies}

In 2016, the average of equivalent tonnes of $\mathrm{CO}_{2}$ emissions per capita in the European Union was 8.7. The countries represented in this collection are dispersed in a relatively balanced way around this value: Hungary (6.3), Switzerland (6.4), the United Kingdom (7.9), Bulgaria (8.4) 
and Slovenia (8.6) see their consumption below the European average, whereas Denmark (9.3), Finland (11.1), Germany (11.4), the Netherlands (12.2) and Ireland (13.5) are above (EEA 2016). Nevertheless, all countries have signed the Paris Agreement based among other factors on a drastic decrease of greenhouse gas emissions, which varies based on country size and energy resources, highlighting the different challenges that these countries are facing towards decarbonisation, and more broadly, towards climate change and pollution mitigation. While there is a common policy agenda around general decarbonisation, there is less consensus around specifics such as nuclear phase out, with opposition movements promoting the increase of nuclear capacity. Some countries, such as Germany and Switzerland, are engaging in policies away from nuclear, while others, such as Hungary, Finland and the United Kingdom, still consider atomic energy as an important part of their energy portfolio.

Energy efficiency is now promoted in all national policies and different ways to achieve efficiencies are put forward and implemented with varying degrees of effectiveness. The material presented in previous chapters of this collection show similarities and differences in the policies of the various states under study. For example, policy documents in Hungary stress the necessity to improve energy efficiency with a strong focus on the household sector and the building stock, but effective policy support has been volatile. Similarly, there is a strong rhetoric supporting energy efficiency in Finland, but actual measures have been relatively limited until recent years. Retrofitting buildings is a widely shared approach to enhance energy efficiency and lower carbon emissions across Europe, but the nature of renewables used between the countries is far from homogenous-which is understandable, given the different natural resources and historical developments. Depending on the climate and the resources available (oil, gas, wood, peat, etc.), different energy portfolios and interests are at stake. There is also an important divide between countries opting for a nuclear phase-out and those in opposition who are working on the expansion of their nuclear capacity. These differences in energy production and management have led to the formation of 'energy islands', with the European Union expressing concerns about the so-called 'fragmentation' of energy policy (Genus and Iskandarova 2018).

The European Union have highlighted some unilateral measures taken by member states, which affect the prices of energy and threaten internal markets. There is thus a call for integration, materialised by the 
European Energy Union, of a strategy made up of various dimensions including the reinforcement of energy efficiency to reduce the European Union dependency on energy imports, and climate actions to decarbonise the economy (European Commission 2018). The Energy Union is being developed in five domains of European Union Energy Policy: (i) security of supply (in 2015, the EU28 imported 54\% of energy supplied); (ii) sustainability (in 2015 fossil fuels contributed $75 \%$ of the fuel mix of EU energy supplied); (iii) greenhouse gas emissions (which for the EU in 2015 was $22 \%$ less than the equivalent measure in 1990); (iv) the role of renewable energy in energy supply and use (accounting for $16 \%$ of final energy consumption for the EU in 2015); and (v) competitiveness of the EU in the energy sector (European Commission 2017, cited in: Genus and Iskandarova 2018: 11).

Energy security is also a key policy issue shaping political interest in energy supply. Here, Coutard and Shove (2018) bring a more nuanced approach to the question of supply and demand, arguing that unlimited and reliable energy has enabled the normalisation of various forms of energy-greedy consumption, from the use of washing machines and refrigerators, to constant ICT connectivity and the increasing use of air-conditioning in certain contexts. Thus, policy framings around energy could also consider 'How much of what is enough?' (Spengler 2016), or offer a more explicit focus on sufficiency. Debates around sufficiency lead into more fundamental and societal questions, such as what services should be enabled, in what contexts, and towards what needs. Taking these debates to heart, and drawing on findings from the H2020 ENERGISE $^{1}$ project, Sahakian et al. (2019) propose a definition of sufficiency which accounts for absolute reductions in resource use, while also challenging collective conventions around household energy use, as well as setting upper (and lower) limits to consumption. This approach is built on the premise that while efficiency is a desired approach towards energy transitions, sufficiency should be considered as the first step. Despite the efforts of projects such as ENERGISE, bringing sufficiency debates and ideas into mainstream political and societal discourse remains a considerable challenge.

\footnotetext{
${ }^{1}$ See www.energise-project.eu.
} 


\section{Socio-Demographic Characteristics}

Socio-demographic characteristics are an important dimension for understanding current energy-related practices and opportunities for change. The usual social categories 'age-gender-(social)class' have effects on how such practices are performed. For example, Gram-Hanssen and Georg (2017) show the link between a person's economic resource, the type of building they live in and their energy habits. Sahakian (2018) also demonstrates the same link in the context of elite households. Economic differences between people lead to different technological acquisition and different habitat conditions, in short, different patterns of consumption. These differences lead several authors to state that thermal conditions should fit the type of building as well as its occupants (Kunkel et al. 2015; Nicol and Wilson 2011; Bopp 2007; Boerstra et al. 2015). The type of occupants and the length of their stay are factors that are classifiable; in other words, they allow standard calculations to apprehend the variability of consumption behaviour. However, as Boerstra et al.'s (2015) critical analysis suggest, these general classifications do not necessarily fit people's perception of comfort and they may lead to higher energy use.

While the links between education levels and energy usage are not linear nor necessarily causal, education levels as a form of social capital may contribute to environmental awareness around energy issues. Age is also seen to have an influence on energy practices, as can be illustrated by the example of laundry. Costanza et al. (2014) suggest that younger people tend to be less predictable in their behaviour and wash at irregular frequencies. Moreover, age has an impact on washing temperatures, as Laitala et al.'s (2012) paper on Norwegian practices indicates. Indeed, they found that younger respondents had lower than average temperatures, and older people had more embedded habits related to washing at hot temperatures.

The location of households, between rural and urban contexts, has a significant influence in the shaping of energy use. It will for instance influence the type and size of the dwelling (e.g. people are more likely to live in a detached house in a rural area), sources of available energy (e.g. district heating may not be an option for rural dwellers) or the connection to the energy system (e.g. the size of a grid can depend on the size of the municipality). Definition of 'urban' and 'rural' varies between countries in Europe, while some countries such as Switzerland and the 
Netherlands also have an intermediate category. The OECD proposes a standardised typology based on three categories: (1) predominantly urban; (2) intermediate; (3) predominantly rural (OECD 2019). With the exception of Slovenia, where more than half of all people live in rural areas, the countries represented in the previous chapters are mostly composed of urban or intermediate populations, with the Netherlands, the United Kingdom and Switzerland associated with the smallest rural populations. These urban-rural divisions can influence household energy demand and related policies.

Dwelling tenure will also determine households' opportunities to reduce energy demand. Previous research highlights the extensive literature on the tenant-landlord relations associated to energy use problematics, pointing out dilemmas such as 'the fact that landlords lack incentives to invest in energy renovations for buildings where the benefits would accrue to tenants or, from the perspective of the tenant, the savings in energy use cannot offset the rent increase due to the renovation' (Laakso and Heiskanen 2017: 12). In this context, Switzerland is the only country under study where the share of rental buildings is higher than that of ownership (Fig. 13.1). Of the countries studied here, Hungary has the highest share of population living in owner-occupied dwellings $(86 \%)$, although they are some way behind Romania $(96 \%)$ as the leading country in the EU.

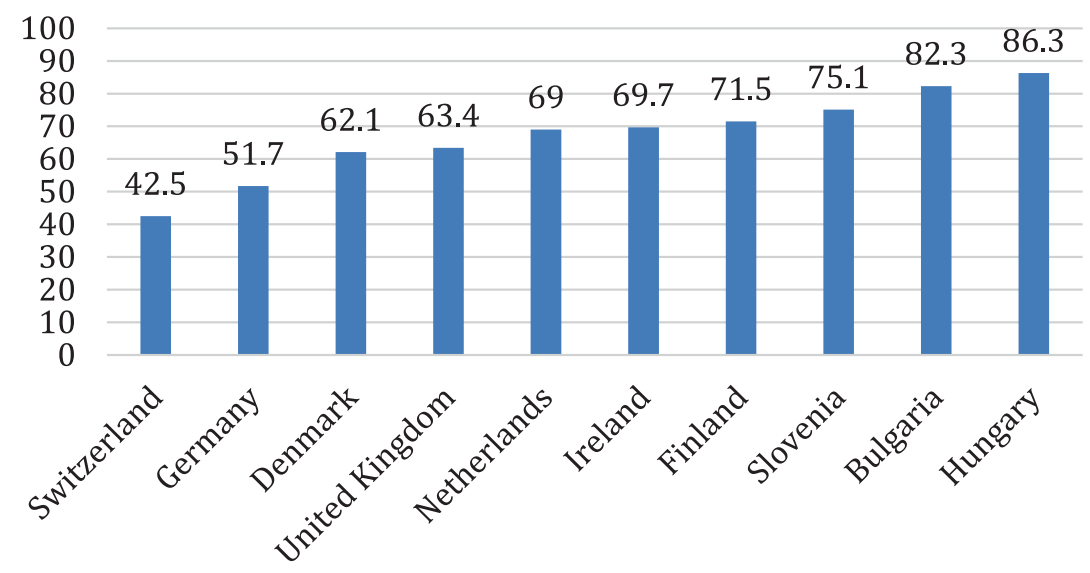

Fig. 13.1 Share of owned dwellings (\%) (Source Eurostat [2018a]) 


\section{Energy Mix and Material Arrangements}

There is significant variation in the energy mix in the residential sector across Europe (Fig. 13.2). Petroleum products are used mainly by Ireland (38\%), Switzerland (34\%) and Germany (22\%), while they are rarely used in Bulgaria (2\%). Countries with the highest proportion of renewable energy usage are Slovenia (45\%) and Bulgaria (33\%), however high levels of domestic wood burning in these countries has led to problems of poor air quality. The Netherlands has only a $5 \%$ share of renewables, however the country projects to increase to $12 \%$ by 2020 ; but the target of $17 \%$ by 2023 may be more realistic. The United Kingdom, with a current share of $4 \%$, has announced that it would provide at least $15 \%$ of its energy from renewable energy sources by 2020 . Gas is predominantly used by the Netherlands (71\%), the United Kingdom (62\%) and Hungary (54\%), while electrical energy is a resource dominant in Bulgaria (42\%) and Finland (37\%), and mobilised in a rather equilibrated way among the remaining countries under study, from $19 \%$ (Hungary) to $29 \%$ (Switzerland).

Regarding house characteristics, the type, age and state of dwellings will determine energy use, especially in terms of investment needed to increase energy efficiency. Such characteristics are linked to social trends,

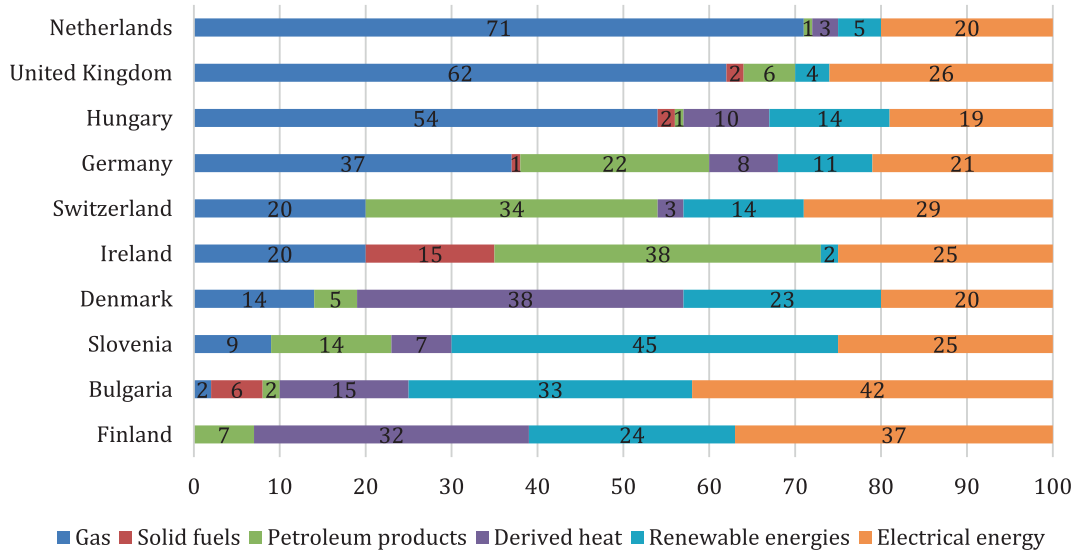

Fig. 13.2 Share of fuels in the final energy consumption in the resident sector, 2015 (\%) (Source Eurostat [2018b]) 
for example towards ever bigger homes and larger window areas. The materials used for the construction of houses have also changed over time, with concrete replacing more traditional materials such as wood and clay. Moreover, the historical development of countries and towns also has an influence on energy use. The necessity for renovation is for instance greater in countries where the building stock is older, such as in Bulgaria where only $5 \%$ of homes were built after 2000. In a comparison of different countries in Europe, Bartiaux et al. (2014) demonstrate how energy-related renovations did not form a unified practice, but rather a bundle of somewhat disjointed practices. In old and poorly maintained buildings, the practices that are likely to save energy can be quite different from those in new and highly automated buildings. For example, the United Kingdom housing stock is one of the oldest compared to most other European countries. Many houses date from the Victorian era and have poor insulation, implying additional energy consumption to maintain a certain level of comfort. However, as the older housing stock is gradually being replaced with a newer one, more energy efficient homes are being developed. In the UK, houses built prior to 1918 represented $25 \%$ of the housing stock in 1970, compared to $16 \%$ in 2014.

The size and type of the dwelling are also important factors determining energy use (Fig. 13.3). On one hand, larger dwellings consume more energy, but on another hand, multiple rooms offer the opportunity for regulating temperatures when rooms are not used. The average dwelling size varies significantly across Europe, ranging from less than $60 \mathrm{~m}^{2}$ in Estonia to more than $120 \mathrm{~m}^{2}$ in Cyprus. In the countries reviewed here, Bulgaria has the smallest average size of residential dwellings (less than $70 \mathrm{~m}^{2}$ ) and Denmark and Ireland have the largest (more than $100 \mathrm{~m}^{2}$ ). Hungary is an interesting case as it is characterised by a large amount of old detached houses: around $63 \%$ of the population (6.5 million people) live in this type of dwelling, generally implying individual heating systems and lower rated insulation. In Hungary, households living in detached houses often use a mix of fuels for heating (e.g. natural gas and wood) and even household waste (despite legal restrictions).

Heating systems and sources are also material conditions influencing household practices related to energy use, with great differences across Europe. Indeed, various sources of energy for heating are predominantly used depending on the countries. One issue with calculating the share of fuels in final energy consumption has to do with definitions of energy sources, and the temporality of the assessment. For example, what 


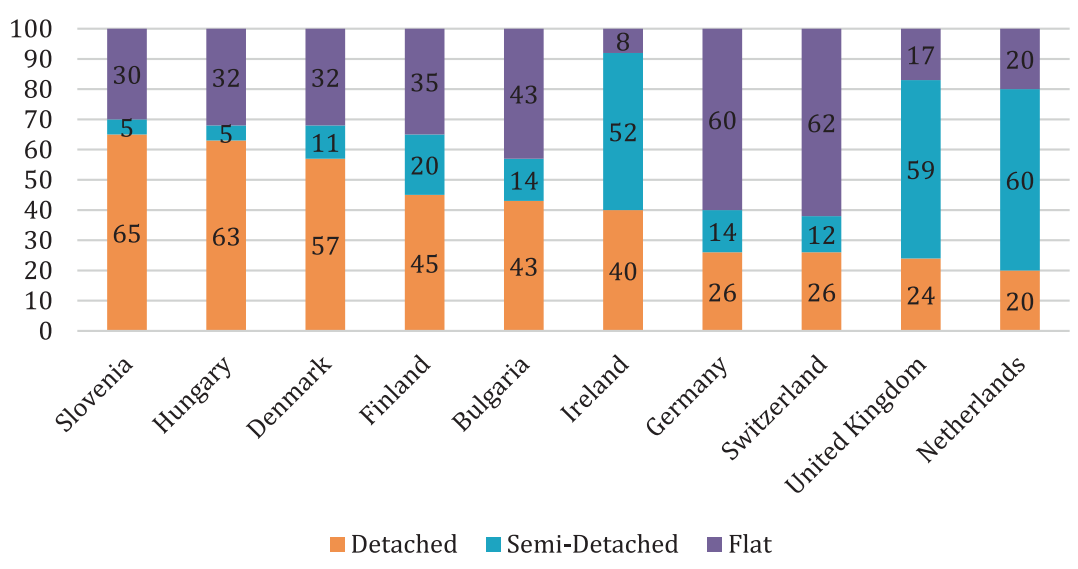

Fig. 13.3 Common dwelling types, 2015 (\%) (Source Eurostat [2017])

is considered as a 'renewable' resource in one context may not be in another (e.g. hydraulic). In the Netherlands and the United Kingdom, households heat space in a large majority with natural gas $(87 \%$ for the Netherlands and 76\% for the United Kingdom). This is also the case, but with a lesser extent, for Hungary (49\%) and Germany (44\%). Renewable energies are the dominant fuel for space heating in Slovenia (63\%) and Bulgaria (58\%), with Hungary using 40\% renewables (note that wood is currently classified as a renewable form of energy). Petroleum products for space heating are used in a very contrasted manner depending on the countries, ranging from almost half of the fuels for Switzerland (46\%) and Ireland (46\%), to being almost zero in Bulgaria, the Netherlands and Hungary. Derived heat is used mostly in Denmark (38\%) and Finland (35\%), but very scarcely in other countries, from 13\% (Switzerland) to 0\% (United Kingdom). Finally, solid fuels and electrical energy are the least used, the former being used most significantly by Ireland (23\%) and the latter by Finland (25\%).

In recent years, the development of 'smart systems' and 'smart cities' has increased to become a global phenomenon. Smart technologies have been progressively integrated in government agendas and considered as a priority area for research. Moreover, smart meters are starting to be installed in homes all over the world towards the goal of 
improving household energy efficiency. Smart technologies can be used to act directly on energy consumption through management of the needed parameters, for instance a smart thermostat for self-regulating homes or self-managing washing machines. The development of smart systems and technologies is at different stages in Europe. Northern European countries are generally the most advanced, already operating smart systems in relation to energy distribution, while other countries are only in a prospective stage, building and implementing strategies. Since 2010, smart energy systems gained momentum in Denmark and Finland, with the latter providing most of its electricity consumers with automatic meter reading installations. Both countries invested significantly in smart grid and smart energy research. Finland is already developing smart products (e.g. Internet of things, building automation, smart controls) for the export market and has around 20 cities piloting smart technologies. In the United Kingdom and the Netherlands, national governments committed to ensuring smart meters for all households by 2020, and smart metering is also part of the 2050 Energy Strategy of Switzerland. Germany is significantly upgrading its electricity grid, integrating smart technologies, and developing the concept of smart cities in major urban areas such as Berlin, Munich, Mannheim and Hamburg.

The number and the ownership of energy suppliers, from private to state-owned, are also elements that may influence household practices in relation to energy usage. State regulations related to energy distribution generally seek to protect consumers' interests and act primarily on the energy bill (adapting the cost of energy between supply and demand for example), which can also shape household energy-usage. For example, regulations to offer low electricity prices based on renewable energy sources might shape the consumer environmental sensitivity. The scale of the production and distribution (municipal, regional, national) of energy will influence the number of suppliers (from one national supplier, to multiple regional or local ones). For example, the Dutch state owned 'Transmission System Operator', owns and operates the high voltage transmission grid at the national level in the Netherlands, but other parts of the grid (lower voltages until 230-400V) are owned and operated by regional energy companies. Switzerland's and Finland's energy systems are also mostly public, but they are operated at the level of municipalities, hence decision-making is decentralised and arguably more responsive to local contextual considerations. 


\section{Climatic Conditions and the Cost of Fuels}

Climatic conditions will also have an influence on how energy-using practices play out, especially in terms of heating and cooling, but also in relation to other practices such as the option for drying clothes outdoors or the necessity to refrigerate foodstuff. The categorisation of different climates varies according to the sources and the description methods, and moreover, climates are far from being homogenous in the whole national territory. In Switzerland, the temperature significantly depends on altitude, with high variation from Arctic to Mediterranean types of climate. Furthermore, climate change will have a significant impact on the Swiss climate: local climatic warming in the Alpine arc is twice as important as the global average. Finland has an annual average temperature of $2{ }^{\circ} \mathrm{C}$ (a little more than $5{ }^{\circ} \mathrm{C}$ in Helsinki on the South Coast and about $0{ }^{\circ} \mathrm{C}$ in Sodankylä in Lapland). Furthermore, this Nordic country is associated with a great variability in the availability of sunlight over the year: during winter solstice, the sun is up for less than 6 hours in Helsinki, and during summer solstice, for almost 19 hours. Thus, with a focus on countries situated in Central and Northern Europe, the main implication for household energy use is related to home heating.

The price of energy in Europe depends on a mix of conditions, including climatic conditions as mentioned above, as well as access to energy sources, and levels of subsidies and taxation. In 2017, the average electricity price for household consumers was 0.20 (Euro per $\mathrm{kWh}$ ) in the European Union ( 0.21 in the European area). The average price of natural gas for EU household consumers was 0.06 Euro per kWh $(0.07$ in the European area), with a range of between 0.04 and 0.11 Euro per $\mathrm{kWh}$. The lowest prices are in Bulgaria and in Hungary (the highest, in Sweden), where the respective governments have an explicit aim to keep household energy prices low, and where access to affordable energy remains an important concern for a large proportion of the population. The cost of electricity may also vary depending on the type of consumer (e.g. household, business, industry), the time of consumption (where day or night rates apply) and the type of the band (kWh capacity). In Germany and Denmark, where systems are mostly operated by private energy companies, the prices are the highest at more than 0.30 Euro per $\mathrm{kWh}$. In contrast, electricity prices in Bulgaria are among the lowest in Europe at less than 0.10 Euro per kWh. 
If we compare the prices of some of the energy sources mentioned above (natural gas, electricity), Bulgaria and Hungary have among the lowest range of prices in Europe, which seems logical since these countries are also the ones with the lowest GDP per capita. Yet, besides this constant, there are some significant differences between the rankings of countries, depending on the resource in question. These variations are of course related to the living standards of these various states, but also to the availability of the resource within their boundaries or the price it costs to import it. For instance, Switzerland is characterised by high prices when it comes to diesel or natural gas-since there are no gas and oil sources in the country-however, the prices of electricity are in the lower range, a situation that could be explained by the important hydroelectric resources present in this mountainous region. In contrast, electricity costs more in Germany than almost anywhere else in Europe, a situation associated with the country's attempt to transition from fossil fuels and nuclear energy to more renewable energy sources. This transition is importantly funded by high taxes on energy companies, as in the case of Denmark, which is also among the most expensive countries in terms of household electricity.

Fuel subsidies also have a role to play on the cost of energy, as do social subsidies indirectly - in that they can provide support for people in need. Framing household's energy practices by suggesting that sustainable behaviours can be financially beneficial is seen to increase acceptance and adoption of sustainable consumption practices. For example, Denmark had a tradition of offering various subsidies, for instance for the installation of solar panels and the replacement of oil burners with heat pumps. Moreover, many subsidies were available in buildings construction and renovation for thermal insulation and double-glazing. However, recent policy changes tend to remove subsidies to households and concentrate on energy savings in business, implying cuts in subsidies to home-renovations.

Several specific campaigns targeting household energy practices have also been promoted this last decade, often based on financial mechanisms. The German government's largest current campaign is the 'Deutschland macht's effizient' initiative focusing primarily on energy efficiency by offering information, consultations and financial incentives in the form of grant aid for households, companies and municipalities who undertake to improve their energy efficiency. In the Netherlands, the 'energy efficiency you do now' programme provides cheap loans for energy efficiency renovations to private home owners and associations of apartment owners. 
The price of energy can influence consumers but is not sufficient in itself to explain energy usage. The cost of energy must be placed in relation to revenues and other household expenditures. Many European countries including the UK, Hungary and Bulgaria are facing particularly important challenges in terms of price and access to energy; it is estimated that fuel poverty affects over $15 \%$ of British households (approximately 4 million) and $21 \%$ of the Hungarian population (Fülöp and Lehoczki-Krsjak 2014). Over $40 \%$ of Bulgarian households are unable to heat their homes to an adequate level. On the contrary, Switzerland, with a relatively high buying power and low prices of electricity (compared to healthcare costs for example) uses a significant amount of electric heating. In Germany, with higher prices of electricity, a lower amount of expensive electric heating is used.

\section{Summary AND Discussion}

In comparing and contrasting energy-related problem framings and social, material and institutional make-up across Europe, this concluding chapter highlights that there is no one-size-fits-all solution to the energy challenge and that policies for energy demand reduction have to carefully consider and address the differences in material and institutional constitutions of energy demand and energy systems, locally, regionally, nationally and cross-nationally. The summaries presented by each country in this edited collection give some interesting insights on what trends are currently underway, and what this implies for the future of energy demand in Europe. The initiatives that focus on household energy reveal interesting findings, such as the importance of EU funding as well as other national funding schemes towards promoting innovative approaches to reduced energy usage, as well as the significance of working with multiple stakeholders towards community engagement, which is seen as preferable to national-led or 'top-down' initiatives. In this vein, there seems to be increasing interest-in policy discourse if not in action-on the need to move away from the 'passive consumer' to the 'active citizen' when it comes to framing the role of households in energy transitions. While most of the energy initiatives seem to be focused on individual and technological change, there are promising examples of how initiatives can also address more complex representations of change. Here, it could be relevant to consider not only the question of access to energy-with energy poverty 
a key issue in several countries, from the UK to Bulgaria-but also upper limits to energy usage, in some contexts and in relation to certain practices.

Another main conclusion is the need to embed energy demand in socio-material systems, tackling questions related to cultural contextfor example, the dominance of 'car culture' in the German case. While the policy and technological dimensions of energy distribution are easier to account for in country reviews, the collective conventions that hold together everyday practices that use energy services are relatively under studied. This relates to a key question in social science approaches to energy: 'how do conventions around energy services evolve, how do they alter over time, and how can they be changed once they are cemented?' (Sovacool 2014: 19). Comparable data is available on energy-related policies, forms of energy provisioning, technological configurations, climatic factors or socio-demographic aspects, to name but a few angles, but there is a lack of comparable empirical data on the collective conventions around energy use and across European countries. The ENERGISE project contributes to this research gap by producing new learnings on social conventions around energy usage across eight countries in Europe, with a focus on heating and laundry, and providing insights on how upper and relative limits to consumption can lead to reflections on 'how much is enough?' (For example, see Sahakian et al. 2019), thus contributing to energy transitions in specific contexts and cultures. In addition, the good practice examples of sustainable energy initiatives provided in this book can serve as inspiration to policy-makers, practitioners, businesses, NGOs, students, academics and others interested in creating a more sustainable and just future.

\section{REFERENCES}

Bartiaux, F., Gram-Hanssen, K., Fonseca, P., Ozolina, L., \& Christensen, T. H. (2014). A practice-theory approach to homeowners' energy retrofits in four European areas. Building Research o Information, 42(4), 525-538.

Boerstra, A. C., van Hoof, J., \& van Weele, A. M. (2015). A new hybrid thermal comfort guideline for the Netherlands: Background and development. Architectural Science Review, 58(1), 24-34.

Bopp, K.-F. (2007). Housing, energy and thermal comfort: A review of 10 countries within the WHO European Region. Copenhagen: WHO Regional Office for Europe. 
Costanza, E., Fischer, J. E, Colley, J. A, Rodde, T., Ramchurn, S. D., \& Jennings, N. R. (2014). Doing the laundry with agents: A field trial of a future smart energy system in the home. In Proceedings of the SIGCHI Conference on Human Factors in Computing Systems, CHI'14 (pp. 813-822). New York, NY: ACM.

Coutard, O., \& Shove, E. (2018). Infrastructures, practices and the dynamics of demand. In E. Shove \& E. Trentmann (Eds.), Infrastructures in practice: The dynamics of demand in networked societies (pp. 10-22). Oxon: Routledge.

EEA. (2016). Greenhouse gas emissions per capita. Accessed 21 March 2019 from https://ec.europa.eu/eurostat/tgm/table.do?tab=table\&init=l\&language $=$ en\&pcode $=$ t2020_rd300\&plugin $=1$.

European Commission. (2018). Energy union and climate. Available at https:// ec.europa.eu/commission/priorities/energy-union-and-climate_en. Accessed 13 November 2018.

Eurostat. (2017). Distribution of population by dwelling type, 2015. Available at http://ec.europa.eu/eurostat/statistics-explained/index.php?title=File:Distribution_of_population_by_dwelling_type,_2015_(\%25_of_population)_ YB17.png. Accessed 21 March 2019.

Eurostat. (2018a). Housing statistics. Available at https://ec.europa.eu/ eurostat/statistics-explained/index.php?title=Housing_statistics. Accessed 21 March 2019.

Eurostat. (2018b). Energy consumption in households. Available at https://ec.europa.eu/eurostat/statistics-explained/index.php/Energy_consumption_in_ households. Accessed 7 June 2018.

Fülöp, O., \& Lehoczki-Krsjak, A. (2014). Energiaszegénység Magyarországon. Statisztikai Szemle, 92(8-9), 820-831 (in Hungarian only). Available at http://www.ksh.hu/statszemle_archive/2014/2014_08-09/2014_0809_820.pdf. Accessed 26 April 2018.

Genus, A., \& Iskandarova, M. (2018). Policy paper 1: State of the art and future of policy integration for EU policy on energy consumption. ENERGISEEuropean Network for Research, Good Practice and Innovation for Sustainable Energy, Deliverable No. 6.4.

Gram-Hanssen, K., \& Georg, S. (2017). Energy performance gaps: Promises, people, practices. Building Research \& Information, 46, 1-9.

Kunkel, S., Kontonasiou, E., Arcipowska, A. Mariottini, F., \& Bogdan, A. (2015). Indoor air quality, thermal comfort and daylight, Buildings Performance Institute Europe (BPIE). Accessed 21 March 2019. http://bpie. $\mathrm{eu} /$ publication/indoor-air-quality-thermal-comfort-and-daylight-an-analysisof-residential-building-regulations-in-8-member-states-2015/.

Laakso, S., \& Heiskanen, E. (2017). Good practice report: Capturing cross-cultural interventions. ENERGISE-European Network for Research, Good Practice and Innovation for Sustainable Energy, Grant Agreement No. 727642, Deliverable No. 3.1. 
Laitala, K., Klepp, I. G., \& Boks, C. (2012). Changing laundry habits in Norway. International Journal of Consumer Studies, 36(2), 228-237.

Nicol, J. F., \& Wilson, M. (2011). A critique of European Standard EN 15251: Strengths, weaknesses and lessons for future standard. Building Research \& Information, 39, 18-193.

OECD. (2019). National area distribution (indicator). Accessed 21 March 2019 from https://doi.org/10.1787/34f4ec4a-en.

Sahakian, M. (2018). Constructing normality through material and social lock-in: The dynamics of energy consumption among Geneva's more affluent households. In H. Allison, D. Rosie, \& W. Gordon (Eds.), Demanding energy: Space, time and change (pp. 51-71). Cham: Springer International Publishing.

Sahakian, M., Naef, P., Jensen, C., Goggins, G., \& Fahy, F. (2019). Challenging conventions towards energy sufficiency: Ruptures in laundry and heating routines in Europe. ECEEE Summer Study 2019 Proceedings.

Sovacool, B. K. (2014). What are we doing here? Analyzing fifteen years of energy scholarship and proposing a social science research agenda. Energy Research \& Social Science, 1, 1-29.

Spengler, L. (2016). Two types of 'enough': Sufficiency as minimum and maximum. Environmental Politics 25(5), 921-940.

Open Access This chapter is licensed under the terms of the Creative Commons Attribution 4.0 International License (http://creativecommons.org/licenses/ by $/ 4.0 /$ ), which permits use, sharing, adaptation, distribution and reproduction in any medium or format, as long as you give appropriate credit to the original author(s) and the source, provide a link to the Creative Commons license and indicate if changes were made.

The images or other third party material in this chapter are included in the chapter's Creative Commons license, unless indicated otherwise in a credit line to the material. If material is not included in the chapter's Creative Commons license and your intended use is not permitted by statutory regulation or exceeds the permitted use, you will need to obtain permission directly from the copyright holder.

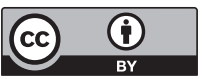

